\title{
Using Teacher Goal Boards to Promote Healthy Eating and Physical Activity among Elementary Students
}

\author{
P. Cougar Hall, Josh H. West, Benjamin T. Crookston, Yvonne Allsop \\ Department of Health Science, Brigham Young University, Provo, UT, USA \\ Email: cougar_hall@byu.edu
}

Received 16 September 2015; accepted 9 November 2015; published 12 November 2015

Copyright (C) 2015 by authors and Scientific Research Publishing Inc.

This work is licensed under the Creative Commons Attribution International License (CC BY). http://creativecommons.org/licenses/by/4.0/

(c) (i) Open Access

\section{Abstract}

Background: The purpose of this study was to explore the feasibility and understand the potential impact on elementary students' perceptions of, and intentions related to, healthy eating and physical activity when their classroom teacher sets and shares goals related to these health behaviors. Methods: Participants in this study included 16 teachers and 229 students of grades $3-6$ at a large elementary school in the Western United States. Participating students were surveyed before and after a six-week intervention conducted by classroom teachers that consisted of a weekly displaying of Teacher Goal Boards in a prominent classroom location and sharing of goals set for the week. Teacher reports of the previous week's goals occurred each Monday prior to sharing and posting of new goals for the new week. Results: Respondents reported significantly higher post-test values for over half of pre-post comparisons. Respondents were more likely to intend to be physically active (post $=52.6 \%$ vs. pre $=39.0 \%, p=0.003)$, to eat nutritious foods $(52.0 \%$ vs. $36.4 \%, p=0.001)$, and to maintain a healthy body weight $(62.8 \%$ vs. $52.2 \%, p=0.022)$. Similar results were found for summary measures. Intention to be physically active, to eat healthy, to maintain a healthy weight, as well as descriptive norms for physical activity and perception and value of personal health behaviors were all significantly higher at post-test. Discussion: This study and its findings are significant because teacher participants were able to significantly and positively impact on students' behavioral intent, subjective norms, and perception and value of personal health behaviors amongst students without spending additional time on formal health promotion and education instruction. Conclusion: Schools should incentivize and encourage faculty and staff to engage in a variety of health behaviors to improve both personal health outcomes and role model health behaviors for students.

\section{Keywords}

Health Education, Health Behavior, School Health, Nutrition, Physical Activity, Elementary Students 


\section{Introduction}

Healthy eating and regular physical activity play a substantial role in preventing chronic disease [1]-[3]. Poor diet and physical inactivity among children increase the risk for chronic health conditions, including high blood pressure, type-2 diabetes, and obesity [3]. The percentage of obese children aged 6 - 11 has tripled over the past 30 years [4]. Obese children have higher rates of social and psychological problems, such as discrimination and poor self-esteem [5]-[8]. Engaging children in healthy eating and regular physical activity can lower these risks and greatly decrease future burdens on health-care and education systems.

Schools play a particularly critical role in improving the physical activity and dietary behaviors of children. With greater than 95\% of children enrolled in schools and in attendance for approximately 6 hours each day [8] schools have unmatched access to young people. School health programs and policies may be one of the most efficient and universal means to prevent or reduce risk behaviors and limit serious health problems among students. Nine guidelines outlining research-based best practices for specifically promoting healthy eating and physical activity have been established by the Centers for Disease Control and Prevention [9]. Each guideline is accompanied by a series of recommendations and strategies for schools to implement. The second guideline addresses the need to establish school environments that support healthy eating and physical activity. Included in this guideline is the recommendation that schools work to establish a psychosocial environment "that encourages and does not stigmatize healthy eating and physical activity" [9]. It is believed that faculty and staff can influence the school environment by working to establish social norms supportive of healthy eating and physical activity [10]. Similarly, the eighth guideline addresses the need for school employee wellness programs to include healthy eating and physical activity goals and services. Activities that promote healthy eating and physical activity among faculty and which emphasize behavioral skills are recommended [9]. Teachers modeling healthy behaviors and skills can help to create a psychosocial climate that encourages students to likewise be physically active and make healthy nutritional choices.

There is strong theoretical support backing the recommendation that schools create an environment supportive of healthy eating and physical activity. Multiple prominent health behavior change theories include constructs related to the example and influence of others. More specifically, several key theoretical constructs support the assertion that referents such as teachers and other school employees who model healthy behaviors can have a powerful influence on the attitudes and behaviors of students. For instance, modeling or observational learning included in Social Cognitive Theory express the impact and influence that observed behaviors have on an individual's decision-making [11]. In particular, the modeling of a desired skill or behavior by a credible role model provides an ideal learning opportunity for the observer who may acquire the targeted skill or behavior through watching the actions and outcomes of others. As Bandura noted, “A good example is therefore a much better teacher than the consequences of unguided actions” [12]. Observations greatly impact on behavior according to the Theory of Planned Behavior as well, where descriptive and injunctive norms included in the subjective norm construct emphasize the impact that an individual's perception of other' beliefs, attitudes and behavior has on his or her own decision-making [13]. Building upon the subjective norm construct, Cialdini, Kallgren, and Reno [14] developed the Focus Theory of Normative Conduct to describe how individuals implicitly juggle multiple behavioral expectations at once; expanding on conflicting prior beliefs about whether cultural, situational or personal norms motivate action, the researchers suggested the focus of an individual's attention will dictate what behavioral expectation they follow. They define a descriptive norm as people's perceptions of what is commonly done in specific situations; it signifies what most people do, without assigning judgment. The absence of trash on the ground in a parking lot, for example, transmits the descriptive norm that most people there do not litter [15] [16]. An injunctive norm, on the other hand, transmits group approval about a particular behavior; it dictates how an individual should behave [15]-[18]. Watching another person pick up trash off the ground and throw it out, a group member may pick up on the injunctive norm that she ought to not litter. Descriptive norms depict what happens while injunctive norms describe what should happen. Collectively, each of these theoretical constructs highlight the influence important referents, such as teachers, can have in shaping the beliefs, attitudes, and behaviors of school children with whom they enjoy a close proximity and regular contact. Despite the belief that modeling healthy behaviors by school personnel is an important factor for promoting health, relatively few studies have explored role-modeling of healthy eating and physical activity among teachers. One notable exception is a study conducted by Kubik, Lytle, Hannan, Story, and Perry [19], which examines the eating behaviors teachers model at school. While nearly all (97\%) of the 490 middle school teachers in this study agreed that a 
healthy school environment was important, the majority did not model healthy eating behavior at school. Most teachers reported high-fat intakes and frequently purchased sweetened soft drinks and high-fat or high-sugar snack foods from school vending machines. A recent observational study of 140 teachers' dietary practices during the school day in Western Saudi Arabia concluded that positive teacher role modeling is necessary in reducing poor dietary behaviors and outcomes among children [20]. Arcan et al. [21] studied classroom food practices and food-related beliefs of 75 kindergarten and first grade teachers on a large American Indian reservation. Many teachers in this study sample did not model healthy eating behavior, yet more than half agreed that students' nutritional choices are influenced by what they see their teachers eat. Power, Bindler, Goetz, and Daratha [22] worked with student, parent, and teacher focus groups to understand how schools might best promote healthy eating and physical activity. Based on their qualitative data, the authors concluded that sending students consistent messages and establishing school-wide social norms supportive of healthy lifestyles is a key to school-based interventions. Hendy and Raudenbush [23] found teacher modeling to have a limited impact on preschoolers' acceptance of new foods. Silent modeling in particular had little sway whereas enthusiastic teacher modeling and peer modeling were of greater effect respectively. Finally, Rossiter, Glanville, Taylor, and Blum [24] examined the classroom food practices, personal health, fat intake, and nutritional knowledge of 103 preservice teachers in Canada. The authors concluded that unhealthy nutritional practices of prospective teachers may act as a barrier to promoting healthy eating and that teachers who fail to model healthy behaviors feel largely hypocritical taking a "Do as I say, not as I do" approach to health promotion in the classroom. While each of these previous studies aimed at understanding teacher modeling of healthy eating or physical activity, to date no study has examined the impact teacher role modeling of goal setting behaviors may have on students' behavioral intentions. The purpose of this study was to understand the potential impact on elementary students' perceptions of, and intentions related to, healthy eating and physical activity when their classroom teacher sets and shares goals related to these health behaviors. The following three research questions guided this study:

1) What impact does an elementary teacher modeling goal-setting behavior related to healthy eating and physical activity have on students' behavioral intentions to eat healthy and be physically active?

2) What impact does an elementary teacher modeling goal-setting behavior related to healthy eating and physical activity have on students' subjective norms related to these health-promoting behaviors?

3) What impact does an elementary teacher modeling goal-setting behavior related to healthy eating and physical activity have on students' perception and value of personal health behavior?

\section{Methods}

\subsection{Participants}

Participants in this study included teachers of grades 3 - 6 and their students at a large elementary school in the Western United States. Slightly more than half (53.9\%) of the students were female whereas $84 \%$ were Caucasian, $5.2 \%$ were Hispanic, and $10.8 \%$ were "other". The largest proportion of students was in the $4^{\text {th }}$ grade (42.1\%) followed by $6^{\text {th }}$ grade $(22.8 \%), 5^{\text {th }}$ grade $(18.5 \%)$, and $3^{\text {rd }}$ grade $(16.7 \%)$. All teachers in grades $3-6$ at the study school were invited to participate. Sixteen of the 23 eligible teachers (70\%) agreed to participate in the study and completed a participant consent form. All students assigned to the classroom of a participating teacher were invited to participate. A combined 229 students of 408 possible student participants (56\%) enrolled in the 16 participating classes agreed to participate in the study and qualified by returning signed child assent and parental/guardian consent forms.

\subsection{Procedure}

Upon approval from the University IRB and the school district Research and Evaluation Chair, researchers met with the principal of the study school to provide an overview of the project and establish a timeline for the intervention. The principal invited all teachers of grades 3 - 6 interested in the study to meet with the principal investigator during the lunch break of a teacher-preparation day prior to the 2013-2014 school year. The principal investigator provided the teachers in attendance an overview of the study, including basic requirements and study incentives. It was explained that participation was voluntary and that participants wanting to discontinue in the study at any time were free to do so with no questions asked. Potential participants were shown a Teacher Goal Board and provided information and a demonstration on setting S-M-A-R-T goals. The Teacher Goal Board was a 24" $\times 36$ " laminated poster with space to write with a dry-erase marker the teacher's weekly 
physical activity, healthy eating, and life-long learning goals (Figure 1). It was explained that teacher participants would be expected to set a S-M-A-R-T goal in each of these three areas (physical activity, healthy eating, and life-long learning) each week for six weeks and report to their students how well they accomplished their goals (Figure 2). Teachers were told that for their participation they would receive, and could keep, a FitBit ${ }^{\circledR}$ Zip accelerometer with a retail value of 60US dollars. All attendees were provided consent forms and instructed

'TWACHER GOAL BOARI)

$\star$ PHYSICAL ACIIVI'IY:

$\star$ HEAL'THY EATING:

$\star$ LIFE-LONG LEARNING:

Figure 1. Teacher goal board.

Use the S-M-A-R-T approach in setting each weekly goal:

Specific and Measurable: Make certain your goals are specific and can be measured. "I will get in shape" or "I will eat better" are both far too general and difficult to measure. "I will walk for 30 minutes five days this week" or "I will eat at least one serving of fruit at breakfast, lunch, and dinner every day this week" are more specific and measurable.

Appropriate and Realistic: On occasion individuals set ill-advised nutrition and exercise goals. Goals such as "I will lose 10 pounds this week" and "I will work out four times a day this week" are likely unsafe and unachievable. The following list includes behaviors recommended by the Centers for Disease Control and Prevention that may help you set appropriate and realistic goals: eat breakfast every day; eat healthy snacks; eat healthy foods when dining out; eat a variety of foods within each food group every day; eat an abundance of fruits and vegetables every day; choose to eat whole grain products and fat-free or low-fat milk; drink plenty of water every day; limit foods and beverages high in added sugars, solid fat, and sodium; engage in moderate to vigorous physical activity every day; engage in warm-up and cool-down activities.

Timed: Every goal needs an end date by which time it will be accomplished. This study includes just short-term goals lasting one week.

Please set your own goals based upon what you personally would like to achieve. The examples of goals in each area listed below are simply to help you begin this process. Challenge yourself with your own goals and have fun!

\begin{tabular}{|c|c|}
\hline Physical Activity & Healthy Eating \\
\hline 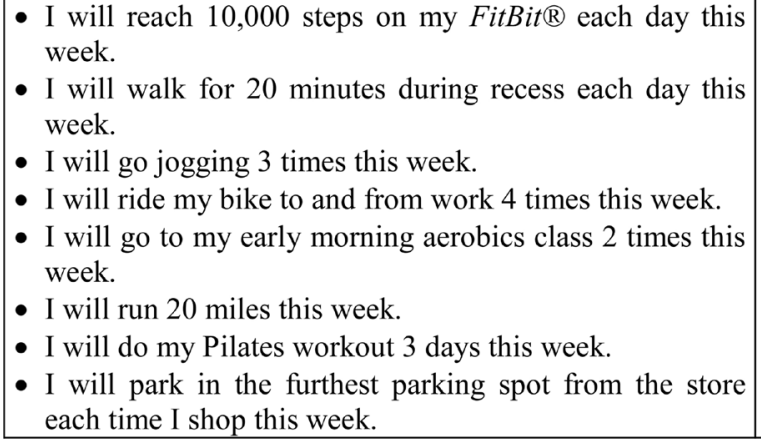 & $\begin{array}{l}\text { - I will eat breakfast every day this week. } \\
\text { - I will not eat or snack after } 8 \mathrm{PM} \text { this week. } \\
\text { - I will eat } 5 \text { servings of vegetables each day this week. } \\
\text { - I will not drink soda this week. } \\
\text { - I will not pass a drinking fountain this week without } \\
\text { stopping for a drink. } \\
\text { - I will replace ice cream with yogurt for dessert this } \\
\text { week. } \\
\text { - I will only use low-fat milk and dressings this week. }\end{array}$ \\
\hline
\end{tabular}

Figure 2. Hidden hollow goal board study guidelines. 
to complete and turn them in to a selected teacher within two weeks if they desired to participate. Consent forms were collected two weeks later by the principal investigator and participating teachers were provided parental/guardian consent forms and child assent forms for each student enrolled in their class. Parents/Guardians and students were informed that participation was voluntary and would not impact class grades. Participating students would receive a healthy snack while completing both the pre- and post-intervention questionnaire. Participating teachers accepted and collected consent and assent forms for two weeks at which time enrollment in the study was closed. A week later the principal investigator administered the student questionnaire in each of the 16 participating classes. On Monday of the following week participating teachers began the day by displaying their individual Teacher Goal Board in a prominent location in the classroom and sharing the goals they had set for the week. The following Monday teachers reported on the previous week's goals before sharing and posting their new goals for the new week.

Teachers responded to student inquiries related to their goal progress as such inquiries arose naturally throughout the week. This weekly goal-setting and reporting routine continued for six weeks. Following the sixweek intervention, the principal investigator returned to each participating classroom to administer both the student questionnaire and the teacher questionnaire.

\subsection{Instrumentation}

Student participants completed the same 20-item questionnaire before and after the six-week intervention. The questionnaire included two demographic questions (sex and race/ethnicity) and 18 questions designed to measure behavioral interventions, subjective norms, and perception and value of personal health behavior [25]. Nine items measured three specific behavioral intentions (healthy eating, physical activity, maintaining a healthy weight) with each behavioral intention addressed by three questions (i.e., I expect to be physically active; I want to be physically active; I intend to be physically active) answered using a 5-point Likert scale (strongly disagree, disagree, neither agree or disagree, agree, strongly agree). Six items measured subjective norms, with three questions specifically targeting descriptive norms (i.e., I think my teacher is physically active; I think that being physically active is important to my teacher; I think that my teacher eats healthy and nutritious foods) and three questions specifically targeting injunctive norms (i.e., I think it is important to my teacher that I engage in physical activity every day; I think it is important to my teacher that I eat healthy and nutritious foods; I think it is important to my teacher that I maintain a healthy body weight). Finally, three items measured student perception and value of personal health behavior (i.e., I am physically active; Physical activity is important to me; I eat healthy and nutritious meals).

Teacher participants completed a brief questionnaire at the conclusion of the six-week intervention which included the following first items: 1) I was motivated to share my Goal Board with my students; 2) I was motivated to set and reach my Goal Board goals; 3) The six-week Goal Board activity was enjoyable for me; 4) I completed the Goal Board activity with my class; and 5) The six-week Goal Board activity was meaningful to my students.

\subsection{Data Analysis}

Change scores were computed using pre- and post-intervention measures of participants’ behavioral intent, subjective norms, and perception and value of personal health behavior. Individual measures were dichotomized as strongly agree vs. all other responses (strongly disagree, disagree, neither agree or disagree, and agree). Summary measures were constructed by averaging the Likert scores across sets of variables. For example, intention to be physically active was constructed by taking the average Likert score of $I$ expect to be physically active, $I$ want to be physically active, and I intend to be physically active. Analogous summary intention measures were constructed for ... eat healthy and nutritious foods and ... maintain a healthy body weight. Summary measures for descriptive and injunctive norms and perception and value of personal health behavior were similarly created using the questions targeting descriptive and injunctive norms and perception and value of personal health behavior described above. Percentages and Pearson chi-square tests were used to compare Likert score means.

\section{Results}

Students had significantly higher post-test responses for over half of pre-post comparisons (Table 1). Students were more likely to intend to be physically active (post $=52.6 \%$ vs. pre $=39.0 \%$, $p<0.003$ ), to eat nutritious 
foods ( $52.0 \%$ vs. $36.4 \%, \mathrm{p}<0.001)$, and to maintain a healthy body weight ( $62.8 \%$ vs. $52.2 \%, \mathrm{p}<0.002)$. There was a significant increase in the belief that the teacher was physically active $(55.9 \%$ vs. $45.7 \%, p<0.028)$ and that the teacher eats healthy and nutritious foods $(53.0 \%$ vs. $43.3 \%, \mathrm{p}<0.036)$, but not in the belief that physical activity is important to the teacher $(59.5 \%$ vs. $53.7 \%, \mathrm{p}<0.028)$. There was no significant improvement in the belief that the teacher felt the student's physical activity, diet, and body weight was important.

Pre-post comparisons for girls and boys differed considerably (Table 2, Table 3). Girls were more likely at

Table 1. Pre- and post-test comparisons of individual health measures, girls $(n=229)$.

\begin{tabular}{|c|c|c|c|}
\hline & Pre & Post & p-value \\
\hline I expect to be physically active & 39.22 & 55.84 & 0.000 \\
\hline I want to be physically active & 51.72 & 67.10 & 0.001 \\
\hline I intend to be physically active & 38.96 & 52.61 & 0.003 \\
\hline I expect to eat healthy and nutritious foods & 41.20 & 49.56 & 0.071 \\
\hline I want to eat healthy and nutritious foods & 50.65 & 56.71 & 0.191 \\
\hline I intend to eat healthy and nutritious foods & 36.36 & 51.95 & 0.001 \\
\hline I expect to maintain a healthy body weight & 55.90 & 63.79 & 0.084 \\
\hline I want to maintain a healthy body weight & 67.39 & 75.65 & 0.050 \\
\hline I intend to maintain a healthy body weight & 52.19 & 62.77 & 0.022 \\
\hline I think my teacher is physically active & 45.65 & 55.90 & 0.028 \\
\hline I think that being physically active is important to my teacher & 53.68 & 59.48 & 0.208 \\
\hline I think that my teacher eats healthy and nutritious foods & 43.29 & 53.02 & 0.036 \\
\hline I think it is important to my teacher that I engage in physical activity every day & 45.69 & 47.41 & 0.710 \\
\hline I think it is important to my teacher that I eat healthy and nutritious foods & 45.06 & 48.71 & 0.431 \\
\hline I think it is important to my teacher that I maintain a healthy body weight & 38.53 & 46.52 & 0.083 \\
\hline I am physically active & 49.13 & 58.87 & 0.036 \\
\hline Physical activity is important to me & 57.52 & 68.26 & 0.018 \\
\hline I eat healthy and nutritious foods & 26.29 & 37.72 & 0.009 \\
\hline
\end{tabular}

Notes: Proportions reported are "strongly agree".

Table 2. Pre- and post-test comparisons of individual health measures, girls $(n=124)$.

\begin{tabular}{|c|c|c|c|}
\hline & Pre & Post & $\mathrm{p}$-value \\
\hline I expect to be physically active & 31.45 & 53.66 & 0.000 \\
\hline I want to be physically active & 47.15 & 68.29 & 0.001 \\
\hline I intend to be physically active & 33.06 & 50.41 & 0.006 \\
\hline I expect to eat healthy and nutritious foods & 45.16 & 44.26 & 0.887 \\
\hline I want to eat healthy and nutritious foods & 50.00 & 57.72 & 0.223 \\
\hline I intend to eat healthy and nutritious foods & 37.10 & 47.15 & 0.109 \\
\hline I expect to maintain a healthy body weight & 55.73 & 62.10 & 0.311 \\
\hline I want to maintain a healthy body weight & 67.48 & 78.23 & 0.058 \\
\hline I intend to maintain a healthy body weight & 48.36 & 62.60 & 0.025 \\
\hline I think my teacher is physically active & 42.74 & 54.55 & 0.065 \\
\hline I think that being physically active is important to my teacher & 54.03 & 61.29 & 0.247 \\
\hline I think that my teacher eats healthy and nutritious foods & 40.65 & 52.42 & 0.064 \\
\hline I think it is important to my teacher that I engage in physical activity every day & 43.55 & 47.58 & 0.524 \\
\hline I think it is important to my teacher that I eat healthy and nutritious foods & 41.13 & 47.58 & 0.307 \\
\hline I think it is important to my teacher that I maintain a healthy body weight & 34.96 & 44.72 & 0.118 \\
\hline I am physically active & 48.78 & 52.85 & 0.524 \\
\hline Physical activity is important to me & 49.58 & 63.41 & 0.030 \\
\hline I eat healthy and nutritious foods & 25.00 & 36.88 & 0.044 \\
\hline
\end{tabular}

Notes: Proportions reported are "strongly agree”. 
Table 3. Pre- and post-test comparisons of individual health measures, boys ( $\mathrm{n}=105)$.

\begin{tabular}{|c|c|c|c|}
\hline & Pre & Post & p-value \\
\hline I expect to be physically active & 48.57 & 57.14 & 0.213 \\
\hline I want to be physically active & 56.60 & 65.71 & 0.175 \\
\hline I intend to be physically active & 46.15 & 55.77 & 0.165 \\
\hline I expect to eat healthy and nutritious foods & 36.79 & 55.34 & 0.007 \\
\hline I want to eat healthy and nutritious foods & 51.92 & 56.19 & 0.536 \\
\hline I intend to eat healthy and nutritious foods & 35.58 & 57.14 & 0.002 \\
\hline I expect to maintain a healthy body weight & 55.77 & 65.71 & 0.141 \\
\hline I want to maintain a healthy body weight & 68.27 & 72.82 & 0.473 \\
\hline I intend to maintain a healthy body weight & 57.28 & 62.86 & 0.412 \\
\hline I think my teacher is physically active & 49.51 & 57.14 & 0.270 \\
\hline I think that being physically active is important to my teacher & 53.85 & 56.19 & 0.733 \\
\hline I think that my teacher eats healthy and nutritious foods & 45.71 & 53.33 & 0.270 \\
\hline I think it is important to my teacher that I engage in physical activity every day & 48.57 & 47.62 & 0.890 \\
\hline I think it is important to my teacher that I eat healthy and nutritious foods & 50.00 & 50.48 & 0.945 \\
\hline I think it is important to my teacher that I maintain a healthy body weight & 52.86 & 49.04 & 0.370 \\
\hline I am physically active & 49.04 & 65.71 & 0.015 \\
\hline Physical activity is important to me & 66.35 & 74.04 & 0.225 \\
\hline I eat healthy and nutritious foods & 28.57 & 36.89 & 0.117 \\
\hline
\end{tabular}

Notes: Proportions reported are "strongly agree".

follow-up to expect, want, and intend to be physically active; to intend to maintain a healthy body weight; to indicate physical activity is important to them; and to report eating healthy and nutritious foods. Conversely, boys were more likely at follow-up to expect, want, and intend to eat healthy and nutritious foods, and to report being physically active. While a number of other comparisons for boys and girls from pre to post were not significant, all but one comparison for each group trended upwards.

Similar results were found for summary measures. Intention to be physically active, eat healthy, maintain a healthy weight, descriptive norms for physical activity, as well as perception and value of personal health behaviors were all significantly higher at post-test (Table 4). For example, the average summary score for intention to be physically active increased from 4.2 to $4.5(\mathrm{p}<0.000)$. Only injunctive norms did not have a significant increase (pre $=4.1$ vs. post $=4.2, \mathrm{p}<0.183$ ). All summary measures for girls were statistically higher after the intervention (Table 5). Half of the summary measures for boys (intention to be physically active, intention to eat healthy, perception and value of personal health behavior) increased significantly (Table 6). Levels of intention to maintain a healthy weight $(\mathrm{p}<0.066)$, descriptive norms $(\mathrm{p}<0.083)$ and injunctive norms $(\mathrm{p}<0.617)$ for boys were the same or higher, but were not significant.

\section{Discussion}

This study sought to answer the following research questions: 1) What impact does an elementary teacher modeling goal-setting behavior related to healthy eating and physical activity have on students' behavioral intentions to eat healthy and be physically active?; 2) What impact does an elementary teacher modeling goal-setting behavior related to healthy eating and physical activity have on students' subjective norms related to these health-promoting behaviors?; and 3) What impact does an elementary teacher modeling goal-setting behavior related to healthy eating and physical activity have on students' perception and value of personal health behavior?

Teacher modeling of goal-setting behavior related to healthy eating and physical activity significantly increased behavioral intentions related to physical activity, healthy eating, and maintenance of a healthy body weight. This finding is particularly encouraging as it provides a strong association between behavioral intentions and actual physical activity and healthy eating among boys and girls [26]-[28]. One unexpected finding 
Table 4. Pre- and post-test comparison by summary measure of health $(\mathrm{n}=229)$.

\begin{tabular}{|c|c|c|c|}
\hline & Pre & Post & p-value \\
\hline Behavioral intent to be physically active & 4.2 & 4.5 & 0.000 \\
\hline Behavioral intent to eat healthy & 4.1 & 4.4 & 0.000 \\
\hline Behavioral intent to maintain a healthy body weight & 4.4 & 4.6 & 0.001 \\
\hline Descriptive norms for health & 4.2 & 4.4 & 0.000 \\
\hline Injunctive norms for health & 4.1 & 4.2 & 0.183 \\
\hline Perception and value of personal health behavior & 4.2 & 4.4 & 0.000 \\
\hline
\end{tabular}

Notes: Intention to be physically active is the average Likert score for "I expect to be physically active", "I want to be physically active", and "I intend to be physically active". Intention to eat healthy is the average Likert score for "I expect to eat healthy and nutritious foods", "I want to eat healthy and nutritious foods", and "I intend to eat healthy and nutritious foods". Intention to maintain a healthy body weight is the average Likert score for "I expect to maintain a healthy body weight", "I want to maintain a healthy body weight", and "I intend to maintain a healthy body weight" The summary measure for descriptive norms is the average Likert score for "I think my teacher is physically active", "I think that being physically active is important to my teacher", and "I think that my teacher eats healthy and nutritious foods". The summary measure for injunctive norms is the average Likert score for "I think it is important to my teacher that I engage in physical activity every day", "I think it is important to my teacher that I eat healthy and nutritious foods", and "I think it is important to my teacher that I maintain a healthy body weight". Student perception and value of personal health behavior is the average Likert score for "I am physically active", "Physical activity is important to me", and "I eat healthy and nutritious meals".

Table 5. Pre- and post-test comparison by summary measure of health, girls $(n=124)$.

\begin{tabular}{lllc}
\hline & Pre & Post & p-value \\
\hline Behavioral intent to be physically active & 4.2 & 4.5 & 0.000 \\
Behavioral intent to eat healthy & 4.2 & 4.4 & 0.007 \\
Behavioral intent to maintain a healthy body weight & 4.5 & 4.6 & 0.001 \\
Descriptive norms for health & 4.3 & 4.5 & 0.000 \\
Injunctive norms for health & 4.1 & 4.4 & 0.008 \\
Perception and value of personal health behavior & 4.2 & 0.000 \\
\hline
\end{tabular}

Notes: Intention to be physically active is the average Likert score for "I expect to be physically active", "I want to be physically active", and "I intend to be physically active". Intention to eat healthy is the average Likert score for "I expect to eat healthy and nutritious foods", "I want to eat healthy and nutritious foods", and "I intend to eat healthy and nutritious foods". Intention to maintain a healthy body weight is the average Likert score for "I expect to maintain a healthy body weight", "I want to maintain a healthy body weight", and "I intend to maintain a healthy body weight". The summary measure for descriptive norms is the average Likert score for "I think my teacher is physically active", "I think that being physically active is important to my teacher", and "I think that my teacher eats healthy and nutritious foods". The summary measure for injunctive norms is the average Likert score for "I think it is important to my teacher that I engage in physical activity every day", "I think it is important to my teacher that I eat healthy and nutritious foods", and "I think it is important to my teacher that I maintain a healthy body weight". Student perception and value of personal health behavior is the average Likert score for "I am physically active", "Physical activity is important to me", and "I eat healthy and nutritious meals".

Table 6. Pre- and post-test comparison by summary measure of health, boys $(\mathrm{n}=105)$.

\begin{tabular}{|c|c|c|c|}
\hline & Pre & Post & p-value \\
\hline Behavioral intent to be physically active & 4.3 & 4.5 & 0.009 \\
\hline Behavioral intent to eat healthy & 4.1 & 4.4 & 0.000 \\
\hline Behavioral intent to maintain a healthy body weight & 4.4 & 4.6 & 0.066 \\
\hline Descriptive norms for health & 4.2 & 4.3 & 0.083 \\
\hline Injunctive norms for health & 4.2 & 4.2 & 0.617 \\
\hline Perception and value of personal health behavior & 4.2 & 4.4 & 0.001 \\
\hline
\end{tabular}

Notes: Intention to be physically active is the average Likert score for "I expect to be physically active", "I want to be physically active", and "I intend to be physically active". Intention to eat healthy is the average Likert score for "I expect to eat healthy and nutritious foods", "I want to eat healthy and nutritious foods", and "I intend to eat healthy and nutritious foods". Intention to maintain a healthy body weight is the average Likert score for "I expect to maintain a healthy body weight", "I want to maintain a healthy body weight”, and "I intend to maintain a healthy body weight". The summary measure for descriptive norms is the average Likert score for "I think my teacher is physically active", "I think that being physically active is important to my teacher", and "I think that my teacher eats healthy and nutritious foods". The summary measure for injunctive norms is the average Likert score for "I think it is important to my teacher that I engage in physical activity every day", "I think it is important to my teacher that I eat healthy and nutritious foods", and "I think it is important to my teacher that I maintain a healthy body weight". Student perception and value of personal health behavior is the average Likert score for "I am physically active", "Physical activity is important to me", and "I eat healthy and nutritious meals". 
from this particular research question relates to a difference in behavioral intentions between girls and boys. Girls reported significantly higher intentions to be physically active compared to boys in the current study. This is promising as both middle and high school-aged females report engaging in significantly less physical activity than their male peers [29]. The current study intervention appears to impact girls' behavioral intent related to physical activity most appropriately. Despite having similar reports at pre-test, girls also reported significantly higher intentions to maintain a healthy body weight compared to boys in the current study. The reason for this difference is unknown yet may relate to dynamics between teachers' sex and students' sex. For example, most of the teachers in this pilot study were female and girls may be more responsive to a female teacher's report of her own health behavior. With only three male teacher participants, exploring such a hypothesis was beyond the scope of the current study, yet could be the focus of a future, larger study of this nature. The current study did not measure students' perceptions of their own weight status, but it is plausible that teachers' reports of their own health-related behaviors were more influential among girls for this reason. It is noted that middle school female students nationally are more likely to describe themselves as slightly or very overweight and report trying to lose weight at a significantly higher rate than male students despite boys being slightly more obese than girls nationally (18.6\% vs. 15.0\%) [29] [30]. Finally, boys' intentions to eat healthy were significantly different at post-test. The current study intervention impacted boys' behavioral intent related to healthy eating most appropriately as female students consume more fruits and vegetables, and less soda or pop than their male counterparts [31]. Summary measures clearly demonstrate the significant and positive impact the current intervention had on students' behavioral intentions related to physical activity, healthy eating, and maintenance of a healthy body weight.

Results of the impact teacher modeling of goal-setting behavior related to healthy eating and physical activity had on subjective norms were mixed. The intervention significantly impacted the descriptive norm, yet did not significantly impact the injunctive norm. Teachers sharing physical activity and healthy eating goals with students increased students' perception of the teacher's physical activity and healthy eating as well as their belief that each of these health-promoting behaviors is important to the teacher. However, teacher modeling did not significantly communicate to students that the teacher felt it important for students to be physically active, eat healthy, and maintain a healthy body weight. It may be that modeling alone is insufficient to significantly impact injunctive norms. It is also possible that students in this study felt valued and accepted unconditionally by teachers, thus buffering the potential impact of modeling on injunctive norms. It is noted that teacher participants were specifically instructed not to directly promote health behaviors to students. It is possible that when combined with classroom health promotion and education efforts, teacher modeling may significantly influence injunctive norms.

Teacher modeling of goal-setting behavior related to healthy eating and physical activity significantly increased student perception and value of personal health behavior. This finding is encouraging in that teacher modeling alone significantly impacted the value students place on physical activity. Teachers are powerful referents in the eyes of young students and when a teacher values a particular health-related behavior, that value can be adopted by students. While the intervention increased perceptions and values related to health behaviors in a positive direction for both girls and boys, only girls showed significant changes on the Physical activity is important to me and I eat healthy and nutritious foods items. Conversely, only boys showed significant changes on the I am physically active item.

This study and its findings are significant because teacher participants were able to significantly and positively impact students' behavioral intent, subjective norms, and perception and value of personal health behaviors amongst students without spending additional time on formal health promotion and education instruction. This is not to say that formal health promotion and education instruction should not occur in elementary classrooms. On the contrary, the authors of this study are adamant supporters of comprehensive pre K-12 school health education and advocate for Coordinated School Health, including increased health education instructional time at the elementary school level. Indeed, this intervention did not address the development of content knowledge or skills related to healthy eating or physical activity that students clearly need to adopt and maintain important health behaviors. Yet with minimal financial cost, minimal classroom time, a short intervention period, and no instructional time or materials, teacher role-modeling of health-related goal-setting had a positive impact on students.

These study results have health promotion implications for school policies and practices. Faculty and staff health promotion, commonly known as employee wellness programs outside of school settings, is an important 
component of Coordinated School Health [32]. Faculty and staff health promotion has been shown to be cost-effective and associated with reduced staff absenteeism [33], improved teacher morale [34], increased physical activity, weight loss, lowered blood pressure, and higher levels of general well-being [35]. While immunizations and flu vaccines are common inclusions in school-based employee wellness programs, less than $50 \%$ of school districts in the US provide physical activity programs for faculty and staff [36]. Policies designed to increase support for, and participation in, school-based faculty and staff physical activity health promotion are both necessary and feasible given the expertise of school district personnel and the health-related resources and facilities found in most school buildings [36]. Health promotion and education practice should be more consistent with theoretical constructs emphasizing the influence of modeling and subjective norms. For example, appropriately sharing the details of faculty and staff health promotion programs, their objectives, and subsequent outcomes with students may improve student health outcomes as well. School health educators may borrow a page form literacy educators who have encouraged teachers to display or discuss the current book or books they are reading in an effort to promote literacy and encourage students to read [37]. Such practices communicate to students that adults read, reading is a normal behavior, and reading is a behavior that the people students look up to enjoy. A similar approach with health-promoting behaviors should be encouraged by policy makers and school administrators. Allowing students to see behind the curtain so to speak, and realize the health-promotion efforts that faculty and staff are engaged in may impact their own behavioral intentions, subjective norms, and perceptions and values of personal health behaviors.

The findings from this study should be interpreted in the context of its limitations. First, study measures may have been difficult for respondents to differentiate. For example, the difference among want, expect, and intend to engage in a health related behavior may have caused some respondents to feel confusion about the questions, provided they each seem similar. This potential limitation is not limited to this study alone, but using recommended analysis methods of creating composite variables to represent prominent theoretical constructs may have minimized the impact [25]. Second, data for this study came from students' self-report, which may be influenced by social desirability to appear conscientious about one's health. It is plausible that some students at post-test remembered their pre-test responses and then intentionally reported higher values at post-test. The principal investigator clearly communicated to the respondents at the administration of both the pre- and post-test that all responses would remain confidential and disassociated from their names with the use of unique identifiers. Lastly, the effects of the brief intervention presented here are measured using pre- and post-test comparisons, without a control group. It is possible that other school-wide initiatives related to physical activity and healthy eating could have also contributed to higher post-test scores. Future research efforts using this brief intervention may benefit from a more rigorous methodology involving randomization of classrooms and a control group.

\section{Conclusion}

This study applied research-based best practices for promoting healthy eating and physical activity in schools as outlined by the Centers for Disease Control and Prevention. Teacher role modeling and sharing of goal setting behaviors related to healthy eating and physical activity had significant positive effects on students' behavioral intentions related to these important behaviors. Ideally schools will incentivize and encourage faculty and staff to engage in a variety of health behaviors to both benefit their own health and set an example for those they teach. A combination of role modeling, deliberately communicating care and concern for students' health behaviors, and providing quality formal classroom health instruction, helps teachers send a clear and consistent health-promoting message to students.

\section{Acknowledgements}

This study was funded by Brigham Young University through a Mentoring Environment Grant.

\section{Human Subjects Approval Statement}

All procedures were approved by the Brigham Young University Institutional Review Board and the Alpine School District Director of Research and Evaluation. Ethical guidelines were strictly followed including participant consent, parental consent, and child assent in English and Spanish. 


\section{References}

[1] Lichtenstein, A.H., Appel, L.J., Brands, M., Carnethon, M., Daniels, S., Franch, H.A., et al. (2006) Diet and Lifestyle Recommendations Revisions 2006: A Scientific Statement from the American Heart Association Nutrition Committee. Circulation, 114, 82-96. http://dx.doi.org/10.1161/CIRCULATIONAHA.106.176158

[2] US Department of Agriculture, Dietary Guidelines Advisory Committee (2010) Report of the Dietary Guidelines Advisory Committee on the Dietary guidelines for Americans, 2010, to the Secretary of Agriculture and the Secretary of Health and Human Services. US Department of Agriculture, Agriculture Research Service, Washington DC.

[3] US Department of Health and Human Services, Physical Activity Guidelines Advisory Committee (2008) Physical Activity Guidelines Advisory Committee Report, 2008. US Department of Health and Human Services, Washington DC.

[4] Ogden, C.L., Carroll, M.D., Curtin, L.R., Lamb, M.M. and Flegal, K.M. (2010) Prevalence of High Body Mass Index in U.S. Children and Adolescents, 2007-2008. Journal of the American Medical Association, 303, 242-249. http://dx.doi.org/10.1001/jama.2009.2012

[5] Daniels, S., Arnett, D., Eckel, R., Gidding, S., Hayman, L., Kumanyika, S., et al. (2005) Overweight in Children and Adolescents: Pathophysiology, Consequences, Prevention, and Treatment. Circulation, 111, 1999-2012. http://dx.doi.org/10.1161/01.CIR.0000161369.71722.10

[6] Dietz, W.H. (2004) Overweight in Childhood and Adolescence. The New England Journal of Medicine, 350, 855-857. http://dx.doi.org/10.1056/NEJMp048008

[7] Institute of Medicine (2004) Preventing Childhood Obesity: Health in the Balance. The National Academies Press, Washington DC.

[8] National Center for Education Statistics (2005) Digest of Education Statistics: 2004. National Center for Education Statistics, Washington DC. http://nces.ed.gov/programs/digest/d04/

[9] Centers for Disease Control and Prevention (2011) School Health Guidelines to Promote Healthy Eating and Physical Activity. Morbidity and Mortality Weekly Report, 60(No. RR-5).

[10] Wechsler, H., Devereaux, R.S., Davis, M. and Collins, J. (2000) Using the School Environment to Promote Physical Activity and Healthy Eating. Preventative Medicine, 31, S121-S137. http://dx.doi.org/10.1006/pmed.2000.0649

[11] Bandura, A. (1977) Social Learning Theory. Prentice Hall, Englewood Cliffs, NJ.

[12] Bandura, A. (1971) Social Learning Theory. General Learning Press, New York.

[13] Ajzen, I. and Fishbein, M. (1980) Understanding Attitudes and Predicting Social Behavior. Prentice Hall, Englewood Cliffs, NJ.

[14] Cialdini, R.B., Kallgren, C.A. and Reno, R.R. (1991) A Focus Theory of Normative Conduct: A Theoretical Refinement and Reevaluation of the Role of Norms in Human Behavior. In: Berkowitz, L., Ed., Advances in Experimental Social Psychology, Academic Press, San Diego, Vol. 24, 201-234.

[15] Cialdini, R.B. (2007) Descriptive Social Norms as Underappreciated Sources of Social Control. Psychometrika, 72, 263-268. http://dx.doi.org/10.1007/s11336-006-1560-6

[16] Cialdini, R.B., Reno, R.R. and Kallgren, C.A. (1990) A Focus Theory of Normative Conduct: Recycling the Concept of Norms to Reduce Littering in Public Places. Journal of Personality and Social Psychology, 58, 1015-1026. http://dx.doi.org/10.1037/0022-3514.58.6.1015

[17] Schultz, P.W., Nolan, J.M., Cialdini, R.B., Goldstein, N.J. and Griskevicius, V. (2007) The Constructive, Destructive, and Reconstructive Power of Social Norms. Psychological Science, 18, 429-434. http://dx.doi.org/10.1111/j.1467-9280.2007.01917.x

[18] Rivis, A. and Sheeran, P. (2003) Descriptive Norms as an Additional Predictor in the Theory of Planned Behaviour: A Meta-Analysis. Current Psychology, 22, 218-233. http://dx.doi.org/10.1007/s12144-003-1018-2

[19] Kubik, M. Leslie, A., Hannan, P., Story, M. and Perry, C. (2002) Food-Related Beliefs, Eating Behavior, and Classroom Food Practices of Middle School Teachers. Journal of School Health, 72, 339-345. http://dx.doi.org/10.1111/j.1746-1561.2002.tb07921.x

[20] Bakhotmah, B. (2012) Teachers Dietary Practices During the School Day in Jeddah, Western Saudi Arabia. Food and Nutritional Sciences, 3, 1553-1560. http://dx.doi.org/10.4236/fns.2012.311203

[21] Aracan, C., Hannan, P., Himes, J., Fulkerson, J., Rock, B., Smyth, M. and Story, M. (2013) Intervention Effects on Kindergarten and First-Grade Teachers' Classroom Food Practices and Food-Related Beliefs in American Indian Reservation Schools. Journal of the Academy of Nutrition and Dietetics, 113, 1076-1083. http://dx.doi.org/10.1016/j.jand.2013.04.019

[22] Power, T.G., Bindler, R.C., Goetz, S. and Daratha, K.B. (2010) Obesity Prevention in Early Adolescence: Student, Parent, and Teacher Views. Journal of School Health, 80, 13-19. http://dx.doi.org/10.1111/j.1746-1561.2009.00461.x 
[23] Hendy, H.M. and Raudenbush, B. (2000) Effectiveness of Teacher Modeling to Encourage Food Acceptance in Preschool Children. Appetite, 34, 61-76. http://dx.doi.org/10.1006/appe.1999.0286

[24] Rossiter, M., Glanville, T., Taylor, J. and Blum, I. (2007) School Food Practices of Prospective Teachers. Journal of School Health, 77, 694-700. http://dx.doi.org/10.1111/j.1746-1561.2007.00253.x

[25] Francis, J.J., Eccles, M.P., Johnston, M., Walker, A., Grimshaw, J., Foy, R., et al. (2004) Constructing Questionnaires Based on the Theory of Planned Behaviour: A Manual for Health Services Researchers. Centre for Health Services Research, University of Newcastle, Newcastle upon Tyne, UK. http://openaccess.city.ac.uk/1735/1/TPB\%20Manual\%20FINAL\%20May2004.pdf

[26] Blanchard, C.M., Kupperman, J., Sparling, P.B., Nehl, E., Rhodes, R.E., Courneya, K.S. and Baker, F. (2009) Do Ethnicity and Gender Matter When Using the Theory of Planned Behavior to Understand Fruit and Vegetable Consumption? Appetite, 52, 15-20. http://dx.doi.org/10.1016/j.appet.2008.07.001

[27] Hagger, M.S., Chatzisarantis, N.L.D. and Biddle, S.J.H. (2002) The Influence of Autonomous and Controlling Motives on Physical Activity Intentions Within the Theory of Planned Behaviour. British Journal of Health Psychology, 7, 283298. http://dx.doi.org/10.1348/135910702760213689

[28] Lien, N., Lytle, L.A. and Komro, K. (2002) Applying Theory of Planned Behavior to Fruit and Vegetable Consumption of Young Adolescents. American Journal of Health Promotion, 16, 189-197. http://dx.doi.org/10.4278/0890-1171-16.4.189

[29] Centers for Disease Control and Prevention (2013) Youth Risk Behavior Survey. www.cdc.gov/yrbs

[30] Ogden, C.L., Carroll, M.D., Kit, B.K. and Flegal, K.M. (2012) Prevalence of Obesity in the United States, $2009-2010$. NCHS Data Brief, No. 82. National Center for Health Statistics, Hyattsville, MD. http://www.cdc.gov/nchs/data/databriefs/db82.pdf

[31] Centers for Disease Control and Prevention (2011) Youth Risk Behavior Survey. www.cdc.gov/yrbs

[32] Allegrante, J.P. (1998) School-Site Health Promotion for Faculty and Staff: A Key Component of the Coordinated School Health Program. Journal of School Health, 68, 190-195. http://dx.doi.org/10.1111/j.1746-1561.1998.tb01299.x

[33] Aldana, S.G., Merrill, R.M., Price, K., Hardy, A. and Hager, R. (2005) Financial Impact of a Comprehensive Multisite Workplace Health Promotion Program. Preventive Medicine, 40, 131-137. http://dx.doi.org/10.1016/j.ypmed.2004.05.008

[34] Allegrante, J.P. and Michela, J. (1990) Impact of a School-Based Workplace Health Promotion Program on Morale of Inner-City Teachers. Journal of School Health, 60, 25-28. http://dx.doi.org/10.1111/j.1746-1561.1990.tb04772.x

[35] Blair, S.N., Collingwood, T.R., Reynolds, R., Smith, M., Hagan, D. and Sterling, C.L. (1984) Health Promotion for Educators: Impact on Health Behaviors, Satisfaction, and General Well-Being. American Journal of Public Health, 74, 147-149. http://dx.doi.org/10.2105/AJPH.74.2.147

[36] Centers for Disease Control and Prevention (2013) Results from the School Health Policies and Practices Study, 2012. US Department of Health and Human Services, Atlanta, GA. http://www.cdc.gov/HealthyYouth/shpps/index.htm

[37] Campbell, R. (1989) The Teacher as a Role Model during Sustained Silent Reading (SSR). Literacy, 23, 179-183. http://dx.doi.org/10.1111/j.1467-9345.1989.tb00364.x 